\title{
Public Understanding Doesn't Always Lead to Public Support
}

\author{
BERNARD DIXON
}

A

fashionable linearity of today runs as follows: Promoting the public understanding of science leads to greater public appreciation of science, which in turn heightens public and political support for science. Whether explicitly stated or not, this theory underpins many of the initiatives to increase scientific literacy that have sprung up around the world in recent years.

But is this theory valid? Do nonscientists really love genetic manipulation more when they are helped to understand it better? Or can greater comprehension have precisely the opposite effect, strengthening existing apprehensions and awakening new ones? And what relationship, if any, exists between a person's overall attitude to science and technology and his or her response to particular issues and developments?

Despite the welter of words already generated on the public's understanding of and attitude toward science, these issues have been comparatively neglected. Now researchers are beginning to realize that some of the most important questions-especially for the biotechnology industry - concern not knowledge or attitude per se but the relationship between the two. One example of the shift in thinking is a paper by Geoffrey Evans of Nuffield College (Oxford, U.K.) and John Durant of Imperial College (London, U.K.) in Public Understanding of Science (4:57-74). Polling a national sample of over 2000 British respondents, they have come up with some of the first real insights into how public understanding relates to public support for science. The results are by no means as one might have predicted.

Evans and Durant first measured general attitudes by asking nine questions, including whether scientists can be trusted, and whether science is changing our way of life too quickly. The results showed a generally positive view of science- $70 \%$ of respondents believing that science and technology are making our lives healthier and more comfortable, and $80 \%$ backing government support for "research that advances the frontiers of knowledge." But the pattern was not uniform - some participants agree with both the positive and negative statements.

To determine whether the subjects' overall view of science was reflected in their opinions on individual areas of research, Evans and Durant used further sets of questions. Specific topics included the desirability of searching for new stars, putting a person on Mars, creating new forms of animal life, and finding a cure for cancer. Here the results revealed a correlation that was at best moderate, being best for useful and basic science, and weakest for morally contentious research. In other words, participants' responses to questions exploring their general attitude toward science and technology did not permit accurate prediction of how they felt about particular types of research.

A third analysis compared the respondents' attitudes to science with their factual knowledge, as assessed from their response to a diversity of statements from the natural and medical sciences-for example, that light travels faster than sound, that diamonds are made of carbon, and that sunlight causes skin cancer. Here Evans and Durant discovered that although there were statistically significant correlations between attitude and knowledge, the strength of the link varied considerably.

Factual knowledge did correlate moderately well with both the participants' attitudes in general and their attitudes toward useful and basic research (as might have been predicted from the link, already demonstrated, between these attitudes). On the other hand, knowledge was almost wholly unrelated to attitudes to nonuseful research. And there was a strong negative association between knowledge and research that can be seen as morally contentious.

Commenting on the tendency for more knowledgeable individuals to express less support for morally contentious research, Evans and Durant conclude that "it would be unwise for scientists and science policy-makers to presume that a better informed public is automatically a public that is more supportive of any and all forms or scientific research. . .On occasion the opinions of a scientifically well-informed public may serve as a check on public and political support for certain areas of research."

Indeed, if greater knowledge also increases the depth of conviction with which views are held, efforts to promote the public understanding of science could even heighten resistance to certain avenues of research. This is an important and thoughtprovoking implication from a meticulously executed piece of research. 